\title{
HUBUNGAN PENGETAHUAN CODER DENGAN KEAKURATAN KODE DIAGNOSIS PASIEN RAWAT JALAN BPJS BERDASARKAN ICD - 10 DI RUMAH SAKIT NIRMALA SURI SUKOHARJO
}

\author{
Widya Kurnianingsih ${ }^{1^{*}}$ \\ ${ }^{1}$ Politeknik Kesehatan Bhakti Mulia Sukoharjo \\ Email: widyakurnianingsih.pbm@gmail.com
}

\begin{abstract}
The hospital is a health care institution in the service of any on coder role in diagnosing the disease effects the income of the hospital. This study aimed to describe the knowledge coder, describe the accuracy of the diagnosis code, and analyze the relationship between knowledge of the coder with the accuracy of a diagnosis code BPJS based outpatient ICD-10 in Sukoharjo Nirmala Suri Hospital The method used in this research is descriptive analytic with cross sectional approach. Coder population that is 6 while the 1,830 documents outpatient medical record documents. The sample 6 used 6 coder and 95 outpatient medical record documents. The instruments used was a questionnaire, interview, observation guidelines, the accuracy of the analysis sheets and ICD-10. Coder sampling technique using saturated sampling, medical record documents using simple random sampling. The results between knowledge coder with the accuracy of a diagnosis code obtained results $\rho$ value 0.050 , then Ho is rejected and $\mathrm{Ha}$ accepted. This shows that there is a relationship between knowledge of the coder with the accuracy of the results above diagnosis with code can be generated strength of the relationship 0.707. Officer of the coding should have knowledge of the procedures for encoding and always meticulous in giving the code and hospitals to be able to provide training for officers coding and socialization to the doctor to write down the diagnosis clear.
\end{abstract}

Keyword: Knowledge Coder, Accuracy code, Outpatient BPJS

\begin{abstract}
ABSTRAK
Rumah sakit merupakan pelayanan kesehatan dalam pelayanan ada salah satu peran coder dalam mendiagnosa penyakit sangat berpengaruh terhadap pendapatan rumah sakit. Penelitian ini bertujuan menganalisis hubungan pengetahuan coder dengan keakuratan kode diagnosis pasien rawat jalan BPJS berdasarkan ICD - 10 di Rumah Sakit Nirmala Suri Sukoharjo. Metode yang digunakan dalam penelitian ini adalah Deskriptif Analitik dengan pendekatan cross sectional. Populasi coder yakni 6 orang sedangkan untuk dokumen 1830 dokumen rekam medis rawat jalan. Sampel yang digunakan 6 orang coder dan 95 dokumen rekam medis rawat jalan. Instrument yang digunakan adalah kuesioner, pedoman wawancara, pedoman observasi, lembar analisis keakuratan dan ICD-10. Teknik sampling coder dengan menggunakan sampling jenuh, dokumen rekam medis dengan menggunakan simple random sampling.Variabel bebas penelitian ini adalah coder, variabel terikat yaitu keakuratan kode diagnosis. Analisis yang digunakan adalah chi Square dengan $\alpha=0,05$. Hasil penelitian berdasarkan uji statistik Chi Square hubungan antara pengetahuan coder dengan keakuratan kode diagnosis didapat hasil $\rho$ value 0,050, maka Ho ditolak dan Ha diterima. Hal ini menunjukkan bahwa ada hubungan antara pengetahuan coder dengan keakuratan kode diagnosis dari hasil diatas dapat dihasilkan keakuratan hubungan 0,707. Dari penelitian ini disarankan bahwa sebagai petugas koding harus mempunyai pengetahuan tentang tata cara pengkodean dan selalu teliti dalam memberikan kode serta rumah sakit untuk dapat memberikan pelatihan bagi petugas koding dan memberikan sosialisasi kepada dokter untuk menuliskan diagnosis dengan jelas.
\end{abstract}

Kata kunci: Pengetahuan Coder, Keakuratan kode, Rawat Jalan 


\section{PENDAHULUAN}

Perkembangan ilmu dan teknologi saat ini mampu menuntun masyarakat untuk lebih memiliki pengetahuan yang luas di segala aspek kehidupan, termasuk dalam aspek kesehatan. Rumah sakit sebagai salah satu sarana pelayanan kesehatan masyarakat diharapkan dapat memberikan pelayanan kesehatan yang sesuai dengan kebutuhan masyarakat, sehingga harus dapat menyelenggarakan pelayananpelayanan kesehatan yang bermutu, salah satunya adalah pelayanan rekam medis. (Azrul, A 1996)

Adanya program pemerintah tentang BPJS ini akan sangat mempengaruhi besaran klaim yang akan di dapat oleh rumah sakit, sehingga perlu adanya tenaga khusus yang dapat mengkoding dengan baik terutama lulusan rekam medis, sehingga lulusan rekam medis harus mempunyai kemampuan salah satunya adalah mengkoding

Rekam medis merupakan salah satu bagian yang penting di rumah sakit dalam membantu pelaksanaan pemberian pelayanan kepada pasien. Hal ini berkaitan dengan isi rekam medis yang mencakup riwayat penyakit pasien, yang meliputi beberapa hal untuk digunakan sebagai dasar pemberian pelayanan selanjutnya dan dasar penentuan diagnosis. Salah satu kegiatan yang dilakukan dibagian rekam medis adalah coding.

Coding adalah pemberian penetapan kode dengan menggunakan huruf atau angka yang mewakili komponen data. Faktorfaktor yang mempengaruhi keakuratan dan ketepatan kode diagnosis ada 3 yaitu tenaga medis, (Dokter pemberi diagnosa), tenaga rekam medis (Coder), dan tenaga kesehatan lainnya (Instansi yang berkaitan seperti perawat, laboratorium, dll), (Depkes, 2006).

Tenaga rekam medis (coder) adalah tenaga rekam medis sebagai seorang pemberi kode bertanggung jawab atas keakuratan kode dari suatu diagnosis yang sudah ditetapkan. Berdasarkan survei awal di Rumah Sakit di rumah sakit Nirmala Suri Sukoharjo bulan Januari 2014 dengan melakukan observasi tentang petugas yang melakukan koding dengan melihat tingkat pendidikannya, pelatihan yang pernah diikuti, lama bekerja dan umur serta mengambil 20 dokumen rekam medis rawat jalan BPJS secara acak, setelah diteliti di Rumah Sakit Nirmala Suri Sukoharjo menunjukkan bahwa terdapat ketidakakuratan kode diagnosis sebanyak $60 \%$ (12 dokumen) yang disebabkan salah satunya karena coder salah dalam memilih diagnosis.

\section{METODE PENELITIAN}

Penelitian ini merupakan kuantitatif menggunakan metode deskriptif analitik. Dengan Pendekatan cross sectiona. Tujuan penelitian ini Untuk menganalisis hubungan pengetahuan coder dengan keakuratan kode diagnosis pasien rawat Jalan BPJS Berdasarkan ICD-10 di Rumah Sakit Nirmala Suri Sukoharjo. Penelitian dilakukan pada seluruh petugas yang mengkode diagnosis pasien rawat jalan BPJS yaitu 6 orang coder dan seluruh dokumen rekam medis rawat jalan BPJS di Rumah Sakit Nirmala Suri Sukoharjo pada tahun 2014 yang berjumlah 1830 dokumen rekam medis Penelitian ini menggunakan teknik pengambilan sampel dengan cara simple random sampling (acak sederhana) yaitu bahwa setiap anggota atau unit dari populasi mempunyai kesempatan yang sama untuk diseleksi sebagai sampel. Penelitian ini pengumpulan data dari kuesioner dan wawancara dilakukan untuk code dan observasi pada dokumen rekam medis rawat inap. Pengolahan data dilakukan untuk coder Editing adalah meneliti untuk setiap daftar pertanyaan yang diisi pada kuesioner, dan meneliti, menjumlah kode diagnosis baik yang akurat maupun tidak akurat. 
Coding adalah memberikan tanda poin pertanyaan di lembar check list dan lembar observasi. Tabulating adalah menyusun data yang telah diperoleh berdasarkan variabel yang diteliti guna memudahkan analisis data. Yaitu dengan mengelompokkan kemudian dihitung dan dijumlahkan. Entry adalah mengolah data dan hasil jawaban dan observasi dari responden dimasukkan kedalam komputer dalam bentuk check list. Analisis data menggunakan spss.

\section{HASIL}

\section{Pengetahuan Petugas Coder}

Dari tabel 1 dapat diketahui sebagian besar petugas mempunyai pengetahuan tentang coding kurang baik yaitu 3 petugas dengan prosentase $50 \%$, sedangkan, 1 petugas mempunyai pengetahuan tidak baik dengan prosentase $16,7 \%$, pengetahuan yang cukup ada 2 petugas dengan prosentase $33,3 \%$.

Tabel 1. Distribusi frekuensi variabel pengetahuan coder di RS. Nirmala Suri Sukoharjo

\begin{tabular}{clrr}
\hline No & Pengetahuan & \multicolumn{1}{c}{ n } & \multicolumn{1}{c}{$\%$} \\
\hline 1 & Baik & 0 & 0 \\
2 & Cukup & 2 & 33.3 \\
3 & Kurang Baik & 3 & 50,0 \\
4 & Tidak Baik & 1 & 16,7 \\
\hline & Jumlah & 6 & 100,0 \\
\hline
\end{tabular}

Tabel 2. Distribusi frekuensi variabel pengetahuan coder berdasarkan petugas di RS. Nirmala Suri Sukoharjo

\begin{tabular}{crrrcc}
\hline Coder & \multicolumn{1}{c}{ B } & \multicolumn{1}{c}{ S } & Jml & $\%$ & Keterangan \\
\hline 1 & 12 & 4 & 16 & 75,0 & Cukup \\
2 & 10 & 6 & 16 & 62,5 & Cukup \\
3 & 4 & 12 & 16 & 25,0 & Tidak Baik \\
4 & 7 & 9 & 16 & 56,3 & Kurang Baik \\
5 & 5 & 11 & 16 & 31,3 & Kurang Baik \\
6 & 6 & 10 & 16 & 37,5 & Kurang Baik \\
\hline
\end{tabular}

Ket: B (Benar); S (Salah); Jml (Jumlah)
Keakuratan Kode Dignosis Pasien Rawat Jalan BPJS Tahun 2015

Dari tabel 3 dapat dilihat bahwa keakuratan kode diagnosis untuk dokumen pasien rawat jalan BPJS yang akurat $69,5 \%$ (66 Dokumen), dan tidak akurat adalah $30,5 \%$ (29 Dokumen). Hal - hal yang mempengaruhi ketidakakuratan kode adalah Kesalahan pada karakter 4, kesalahan pada pemberian kode dan penulisan yang tidak jelas.

Tabel 3. Distribusi Frekuensi variabel keakuratan kode diagnosis pasien rawat jalan BPJS di RS. Nirmala Suri Sukoharjo

\begin{tabular}{clcc}
\hline No & $\begin{array}{c}\text { Keakuratan } \\
\text { Kode Diagnosis }\end{array}$ & $\begin{array}{c}\text { Jumlah } \\
\text { (DRM) }\end{array}$ & $(\%)$ \\
\hline 1 & Akurat & 66 & 69,5 \\
2 & Tidak Akurat & 29 & 30,5 \\
& Jumlah & 95 & 100 \\
\hline
\end{tabular}

Tabel 4. Distribusi frekuensi variabel keakuratan kode diagnosis berdasarkan coder di RS. Nirmala Suri Sukoharjo

\begin{tabular}{|c|c|c|c|c|c|}
\hline Coder & $\mathrm{A}$ & TA & $\mathrm{Jml}$ & $\%$ & Ket. \\
\hline 1 & 15 & 2 & 17 & 88,2 & Akurat \\
\hline 2 & 14 & 3 & 17 & 82,3 & Akurat \\
\hline 3 & 10 & 5 & 15 & 66,7 & $\begin{array}{l}\text { Tidak } \\
\text { Akurat }\end{array}$ \\
\hline 4 & 12 & 4 & 16 & 70,8 & $\begin{array}{l}\text { Tidak } \\
\text { Akurat }\end{array}$ \\
\hline 5 & 7 & 9 & 16 & 43,7 & $\begin{array}{l}\text { Tidak } \\
\text { Akurat }\end{array}$ \\
\hline 6 & 8 & 6 & 14 & 57,1 & $\begin{array}{l}\text { Tidak } \\
\text { Akurat }\end{array}$ \\
\hline
\end{tabular}

$\begin{array}{llll}\text { Total } & 66 & 29 & 95\end{array}$

Ket: A (Akurat); TA (Tidak Akurat); Jml (Jumlah); Ket (keterangan)

\section{Hubungan Pengetahuan Coder dengan keakuratan kode diagnosis pasien rawat jalan BPJS}

Berdasarkan tabel 5 dapat dilihat bahwa Keakuratan kode diagnosis dari coder yang mempunyai pengetahuan cukup diagnosa yang dihasilkan akurat prosentase $33,3 \%$ dan yang mempunyai pengetahuan coder yang kurang baik dan tidak baik 
Tabel 5. Analisis Bivariat antar variabel di Rumah Sakit Nirmala Suri Sukoharjo

\begin{tabular}{|c|c|c|c|c|c|c|c|c|}
\hline \multirow{3}{*}{ Pengetahuan Coder } & \multicolumn{4}{|c|}{ Keakuratan Kode Diagnosis } & \multicolumn{2}{|c|}{ Jumlah } & \multirow{3}{*}{ Sig } & \multirow{3}{*}{$\mathrm{C}$} \\
\hline & \multicolumn{2}{|c|}{ Akurat } & \multicolumn{2}{|c|}{ Tidak Akurat } & & & & \\
\hline & $\mathrm{n}$ & $\%$ & $\mathrm{n}$ & $\%$ & $\mathrm{n}$ & $\%$ & & \\
\hline Baik & 0 & 0,0 & 0 & 0,0 & 0 & 0,0 & & \\
\hline Cukup & 2 & 33,3 & 0 & 0,0 & 2 & 50,0 & & \\
\hline Kurang Baik & 0 & 0,0 & 3 & 50,0 & 3 & 50,0 & 0,050 & $0, / 0 /$ \\
\hline Tidak Baik & 0 & 0,0 & 1 & 16,7 & 1 & 0,0 & & \\
\hline Jumlah & 2 & 50,0 & 4 & 50,0 & 6 & 100,0 & & \\
\hline
\end{tabular}

keakuratan kodenya tidak akurat yaitu $50 \%$ dan $16,7 \%$ sehingga akan didapatkan nilai signifikan 0.050 dari hasil maka hubungan pengetahuan coder dengan keakuratan kode diagnosis mempunyai hubungan yang signifikan.

\section{PEMBAHASAN}

Pengetahuan Petugas Pengkodean Diagnosis Pasien Rawat Jalan BPJS Tahun 2014 Di Rumah Sakit Nirmala Suri Sukoharjo

Berdasarkan Tabel 1 hasil analisis pengetahuan coder dari ke 6 responden yang diamati menunjukkan bahwa tingkat pengetahuan coder di Rumah Sakit Nirmala Suri Sukoharjo sebanyak 3 responden $(50 \%)$ diketahui tingkat pengetahuannya kurang baik dan ada 1 responden dengan pengetahuan tidak baik. Hal ini dikarenakan bahwa 2 responden adalah lulusan SMA tidak sama sekali melakukan pelatihan tentang kode dan salah satunya adalah lulusan D III - Non RM lama bekerja dari ketiga responden lebih dari 5 tahun. Sehingga untuk ilmu mengkoding kurang dikuasai.

Berdasarkan hasil analisis diatas untuk mencapai pengetahuan baik yang paling berpengaruh yaitu dari faktor pendidikan karena lulusan dari rekam medis mempunyai kompetensi tentang mengkoding akan tetapi selain sudah didukung dari pendidikan D3-RM, dari responden tersebut perlu adanya pelatihan tentang koding agar menunjang pengetahuan mereka dalam mengkode diagnosis menggunakan ICD-10 yang dilakukan sebagai dasar dalam melakukan pengkodean diagnosis pasien.

\section{Keakuratan Kode Diagnosis Pasien Rawat Jalan BPJS Pada Tahun 2014 Di Rumah Sakit Nirmala Suri Sukoharjo}

Berdasarkan hasil analisis di atas di Rumah Sakit Nirmala Suri Sukoharjo masih banyak ditemukan ketidak akuratan kode diagnosis hal ini sangat berdampak terhadap besarnya klaim yang dibayarkan karena besarnya biaya klaim tergantung dari kode diagnosis yang dimasukkan ke dalam program INA-CBGs, sehingga ketidak akuratan kode diagnosis ini akan membawa dampak besar terhadap pendapatan Rumah Sakit. Rumah Sakit dapat mengalami kerugian akibat ketidaksesuaian jumlah klaim yang dibayar dengan besaran biaya yang telah dikeluarkan oleh Rumah Sakit untuk suatu pelayanan dan juga termasuk rumah sakit swasta jika banyak klaim yang tidak sesuai maka lama kelamaan biaya operasional akan mati.

Ketidakakuratan kode diagnosis yang terjadi tersebut tentunya tidak bisa dibiarkan begitu saja, sehingga Rumah Sakit harus mempunyai solusi untuk mengatasi masalah tersebut. Berdasarkan observasi yang dilakukan untuk dapat meminimalisir ketidaktepatan kode diagnosis, diantaranya yaitu mengembalikan berkas rekam medis 
pasien yang tidak lengkap ke ruang perawatan agar dilengkapi oleh dokter atau perawat yang bersangkutan, meminta dokter untuk mengisi diagnosis sesuai dengan standar yang ada pada ICD-10 dan ditulis dengan jelas. Hal tersebut sesuai dengan ketentuan yang terdapat dalam Permenkes No. 269 Tahun 2008 bahwa setiap dokter wajib membuat rekam medis dan menegakkan diagnosis yang tepat dan jelas.

Penyebab dari ketidakakuratan kode diagnosis tersebut berdasarkan observasi kepada 6 responden adalah sebagai berikut :

a. Diagnosis yang ditetapkan oleh dokter tidak spesifik misalnya untuk letak anatomi dan fisiologinya tidak dituliskan, sehingga menyulitkan coder dalam memilih kode diagnosis utamanya dengan tepat.

b. Tulisan diagnosis yang ditetapkan oleh dokter tidak terbaca, sehingga menyulitkan petugas coder dalam memberikan kode diagnosis.

c. Faktor komunikasi yang kurang antara petugas karena selalu ada pergantian petugas.

d. Kurang teliti petugas coder dalam membaca tulisan dokter dan dalam memberikan kode diagnosis pasien,

e. Petugas coder dalam melakukan pengkodean diagnosis tidak sesuai dengan protap yang ada di Rumah Sakit Nirmala Suri Sukoharjo yaitu ditemukan masih sering tidak menggunakan buku ICD-10 dalam menetapkan kode diagnosis tetapi hanya menggunakan buku pintar.

Hal ini sesuai dengan pendapat sudra (2008), bahwa faktor - faktor yang mempengaruhi keakuratan kode diagnosis, antara lain :

a. Kelengkapan diagnosis

b. Kemampuan petugas koding untuk membaca diagnosis dengan benar

c. Kemampuan petugas koding untuk memahami terminologi medis d. Beban kerja petugas koding

e. Sarana kerja yang tersedia

f. Sarana komunikasi di tempat kerja perlu dipertimbangkan apakah tersedia kemudahan telepon, intercom, atau sejenisnya agar petugas koding mudah konsultasi dengan dokter yang menuliskan diagonosis.

g. Masih perlu dipertimbangkan juga kemampuan koding untuk berkomunikasi secara efektif dan efisien dengan berbagai pihak terutama dengan dokter yang menuliskan diagnosis.

\section{Hubungan Pengetahuan Coder Dengan Keakuratan Kode Diagnosis Pasien Rawat Jalan BPJS Pada Tahun 2014 Di Rumah Sakit Nirmala Suri}

Hubungan pengetahuan coder dengan keakuratan kode diagnosis pasien rawat jalan pada tahun 2014 di Rumah Sakit Nirmala Suri Sukoharjo berdasarkan hasil perhitungan uji statistic dengan chi square diperoleh nilai sig 0,050, maka Ho ditolak dan $\mathrm{Ha}$ diterima artinya pengetahuan petugas pemberi kode diagnosis mempunyai hubungan yang signifikan dengan keakuratan kode diagnosis pasien rawat jalan BPJS berdasarkan ICD-10. Berdasarkan dari hasil analisis diperoleh nilai C (Koefisien kontingensi) sebesar 0,707 , hal ini berarti kekuatan atau tingkat hubungan antara pengetahuan petugas coding dengan keakuratan kode diagnosis tergolong tingkat hubungannya kuat.

Hal ini sesuai dengan yang tertuang dalam Depkes (2006) bahwa yang menyebabkan ketidak akuratan kode diagnosis salah satunya adalah petugas rekam medis (coder) yang bertanggungjawab dalam pemberian kode diagnosis pasien yang telah ditetapkan oleh dokter. Salah satu faktor yang menyebabkan coder salah dalam pemberian kode diagnosis adalah kurangnya pengetahuan coder tentang tata cara penggunaan ICD-10 dan 
ketentuan-ketentuan yang ada didalamnya serta pengetahuan penunjang lainnya yang berkaitan dengan koding dan yang mendukung ketepatan dalam pemberian kode diagnosis.

\section{SIMPULAN}

1. Pengetahuan coder dari 6 responden yang diamati dihasilkan data sebagai berikut : Cukup yaitu 33,3 \% (2 Petugas), Kurang baik yaitu $50 \%$ (3 Petugas) dan tidak baik $16,7 \%$ (1 Petugas).

2. Keakuratan kode diagnosis pasien rawat jalan BPJS pada tahun 2015 berdasarkan penelitian terhadap 6 orang coder dan 95 dokumen yang diamati ditemukan data sebagai berikut : pengkodean akurat 33,3 \% (2 Petugas) dan pengkodean tidak akurat $66 \%$ (4 petugas), dan dapat disimpulkan secara keseluruhan bahwa kode diagnosis Akurat yaitu 66,5\% (66 dokumen) dan kode diagnosis tidak akurat sebesar $30,5 \%$ (29 dokumen)

3. Ada hubungan pengetahuan coder dengan keakuratan kode diagnosis pasien rawat jalan BPJS berdasarkan ICD-10 di Rumah Sakit Nirmala Suri. Hal ini dibuktikan dari hasil perhitungan chi square diperoleh nilai signifikan $0,05(0,05 \leq 0,05)$, dan dari nilai $\mathrm{C}$ (Koefisien kontingensi) sebesar 0,707, hal ini berarti tingkat hubungannya tergolong kuat.

4. Bagi coder untuk bisa lebih teliti dalam memberikan kode diagnosis dan selalu menggunakan buku ICD - 10 jangan hanya menggunakan buku catatan kecil.

5. Rumah Sakit mengadakan pelatihanpelatihan tentang koding bagi coder agar mempunyai keterampilan dalam memberikan kode diagnosis yang telah ditetapkan dokter. Jika merekrut karyawan akan lebih baik jika menerima dari lulusan D III- Rekam Medis karena akan sangat berpengaruh kepada sistem pengkodean.

6. Disarankan pihak rumah sakit memberikan sosialisasi kepada para dokter untuk melengkapi dokumen rekam medis yang tidak lengkap dan memberikan diagnosis yang sesuai dengan ketentuan yang ada di dalam ICD-10 dan menuliskan diagnosis tersebut dengan jelas agar coder dapat membacanya.

\section{DAFTAR PUSTAKA}

Azrul, A. 1996. Pengantar Administrasi Kesehatan. Jakarta: Binapura Aksara, Edisi 3.

Arikunto, S. 2006. Prosedur Penelitian Suatu Pendekatan Praktek. Jakarta Rineke Cipta

Arisona, Sefi. 2013. Hubungan Kelengkapan Pengisian resume Medis Dengan Keakuratan Kode Diagnosis Pasien Obstetri Berdasarkan ICD-10 DI Instalasi Rawat Inap RSUD Dr. Moewardi. Skripsi Univet Sukoharjo.

Budiarto, E. 2001. Pengantar Kesehatan Masyarakat. Semarang : UNDIP

Dahlan, Sopiyudin M. 2009. Statistik Untuk Kedokteran dan Kesehatan. Jakarta : Salemba Medika

Depkes RI. 2006. Pedoman Pengelolaan Rekam Medis Rumah Sakit Indonesia. Jakarta.

1999.Pedoman Penggunaan ICD-10 Seri I. Jakarta

Dina Ayu Fitriana (2013), tinjauan keakuratan kode diagnosis kasus kehamilan dan persalinan berdasarkan icd-10 pada dokumen rekam medis rawat inap di rumah sakit amal sehat slogohimo wonogiri tahun 2013. KTI Bhakti Mulia

Hatta, G. R. 2008. Pedoman Manajemen Informasi Kesehatan Di Sarana Pelayanan Kesehatan Revisi Buku 
Petunjuk Teknis Penyelenggaraan Rekam Medis atau Medical Record Rumah Sakit Di Indonesia. Jakarta: UI Press

.2012. Pedoman Manajemen Informasi Kesehatan di Sarana Pelayanan Kesehatan. Jakarta: Universitas Indonesia (UI - PRESS).

Hidayati A. A. 2007. Metode Penelitian Kebidanan dan Teknik Analisis Data. Jakarta: Salemba Medika

Ike Yuliana (2013) tinjauan kodifikasi carcinoma mammae pada dokumen rekam medis pasien rawat inap berdasarkan icd-10 di rumah sakit umum daerah dr. Moewardi tahun 2013. Skripsi Esa Unggul.

Keputusan Menteri Kesehatan. 2007. No. 377/Menkes/PER/SK

III/2007

tentang Standar profesi perekam medis dan informasi kesehatan.

.2013. Undang - Undang Tentang BPJS.

Kumala, Poppy...(et. A1.) ; copy editor bahasa Indonesia, Dyah Nuswantari. -Ed.25-. 1998. Kamus Saku Kedokteran Dorland/ alih bahasa. Jakarta : EGC

Lily Kresnowati. 2013. Analisis Faktorfaktor Yang Mempengaruhi Akurasi Koding Diagnosis Dan Prosedur Medis Pada Dokumen Rekam Medis Di Kota Semarang.

Manangka, F. R. 1998. Klasifikasi Statistik Internasional Tentang Penyakit Dan Masalah Kesehatan (ICD-10) Petunjuk Penggunaan ICD-10. Surabaya : K.P.R.I Dr. Soetomo

Notoadmojo, S. 2007. Ilmu Kesehatan Masyarakat. Jakarta : Rineke Cipta 2012. Metodologi Penelitian Kesehatan. Jakarta : Rineke Cipta

Rahayu, W.A. 2013. Kode Klasifikasi Penyakit dan Tindakan Medis ICD-10 Yogyakarta : Gosyen Publishing
Republik Indonesia. 2009. Undang - undang Nomor 44 Tahun 2009 tentang Rumah Sakit. Jakarta

Rustiyanto, Ery. 2010. Statistik Rumah Sakit Untuk Pengambilan Keputusan. Yogyakarta : Graha Ilmu

Saryono, dan Anggraeni, Mekar Dwi. 2013. Metodologi Penelitian Kualitatif dan Kuantitatif dalam Bidang Kesehatan. Yogyakarta : Nuha Medika

Shofari, B. 2002. Pengelolaan Sistem Pelayanan Rekam Medis di Rumah Sakit. Jakarta : Rineka Cipta

SK Menkes RI No : 377/Menkes/SK III/ 2007. Tentang Rekam Medis

Sudra, IR. Konsultasi-Faktor yang berperan dalam akurasi pengkodean.

Sugiyono. 2006. Statistika untuk penelitian. Bandung : CV. Alfabeta

WHO. 2010. International Statistical Clasification Of Disease And Related Health Problem Tenth Revision Volume 1. Geneva : WHO 2010. International Statistical Clasification Of Disease And Related Health Problem Tenth Revision Volume 2. Geneva : WHO 2010. International Statistical Clasification Of Disease And Related Health Problem Tenth Revision Volume 3. Geneva : WHO 